\title{
Diyet Enerji Yoğunluğunun Diyet Kalitesi ve Antropometrik Ölçümler ile İlişkisi
}

\author{
The Relationship of the Diet Energy Density with the Diet Quality and the Anthropometric \\ Measurements
}

Meltem Pınar Yıldırım¹, Burcu Ateş Özcan ${ }^{2}$

Geliş tarihi/Received: 01.12.2020 • Kabul tarihi/Accepted: 29.05.2021

\section{ÖZET}

Amaç: Bu çalışma, yetişkin bireylerde diyet enerji yoğunluğunun, diyet kalitesi ve antropometrik ölçümler ile olan ilişkisini incelemek amacıyla yapılmıştır.

Bireyler ve Yöntem: Çalışmaya 19-65 yaş arası 271 yetişkin dâhil edilmiştir. Katılımcılara sosyo-demografik verilerinin sorgulandığı bir anket formu yüz yüze görüşme yöntemi ile uygulanmış, bireylerin antropometrik ölçümleri alınmıştır. Ayrıca katılımcılardan 24-saatlik geriye dönük besin tüketim kaydı alınmıştır. Besin tüketim kaydı aracılığı ile diyet kalitesi ve diyet enerji yoğunluğu hesaplanmıştır. Diyet kalitesinin belirlenmesinde "Diyet Kalite İndeksi-Uluslararası (DKİ-U)" ölçeği kullanılmıştır. Diyet enerji yoğunluğu ise "sadece katı yiyecekler” ve "katı yiyecekler + içecekler” olmak üzere iki farklı hesaplama yöntemi kullanılarak hesaplanmıştır.

Bulgular: Çalışmaya katılan bireylerin yaş ortalamaları $27.9 \pm 10.60$ yıldır. Katılımcıların "sadece katı yiyecekler” ortalama diyet enerji yoğunluğu $1.43 \pm 0.49 \mathrm{kkal} / \mathrm{g}$, "katı yiyecekler + içecek” ortalama diyet enerji yoğunluğu $1.19 \pm 0.42 \mathrm{kkal} / \mathrm{g}$ olup, erkeklerin ortalama değerleri kadınlardan daha yüksektir ( $p>0.05$ ). Katılımcıların diyet kalite indeksi $47.8 \pm 9.79$ puan olup erkeklerin indeks puanları kadınlardan daha yüksektir ( $p>0.05$ ). Diyet kalitesi iyi olan katılımcıların diyet enerji yoğunluğu, kötü olanlara kıyasla daha düşüktür ( $p<0.001$ ). Her iki yöntemle hesaplanan diyet enerji yoğunlukları ile diyet kalitesi arasında negatif yönlü anlamlı ilişki saptanırken, antropometrik ölçümler ile diyet kalitesi arasında bir ilişki saptanamamıştır.

Sonuç: Diyet enerji yoğunluğunun yüksek olması, diyet kalitesinin kötü olması ile ilişkilendirilirken, beden kütle indeksi, vücut ağırlığı, bel/boy ve bel/kalça oranları ile istatistiksel olarak anlamlı ilişkiler saptanamamıştır. Diyet kalitesinin kötü olması ve yüksek enerji yoğunluklu beslenmenin sağlık üzerine olumsuz etkilerini gösteren çalısmalar göz önünde bulundurulduğunda, diyet kalitesini arttıracak enerji yoğunluğu düşük bir beslenme tarzının benimsenmesi önemlidir. Diyet enerji yoğunluğunun antropometrik ölçümler ile ilişkisini yansıtan daha çok çalışmaya ihtiyaç duyulmaktadır.

Anahtar kelimeler: Diyet enerji yoğunluğu, diyet kalitesi, beden kütle indeksi, antropometrik ölçümler, beslenme

\section{ABSTRACT}

Aim: This study was conducted to examine the relationship between dietary energy density, diet quality and anthropometric measurements in adults.

1. İletişim/Correspondence: İstanbul Okan Üniversitesi, Sağllk Bilimleri Enstitüsü, İstanbul, Türkiye

E-posta: dyt.mpinaryildirim@gmail.com • ㄴ https://orcid.org/0000-0001-9999-4786
2. İstanbul Okan Üniversitesi, Sağllk Bilimleri Fakültesi, Beslenme ve Diyetetik Bölümü, İstanbul, Türkiye • • \ https://orcid.org/0000-0003-2627-0167 
Subjects and methods: 271 adults between the ages of 19-65 were included in the study. A questionnaire examining the sociodemographic data of the participants was applied by face to face interview method, and the anthropometric measurement values of the individuals were obtained. Additionally, a 24-hour retrospective dietary intake record was obtained from the participants. Diet quality and diet energy density were calculated through dietary intake record. "Diet Quality Index-International (DQI-I)" was used in determining the diet quality. Dietary energy density was calculated using two different calculation methods: "solid only" and "solid + drinks".

Results: The mean age of the individuals participated in the study was $27.9 \pm 10.60$ years. The average dietary energy density of the participants "solid only" was $1.43 \pm 0.49 \mathrm{kcal} / \mathrm{g}$, "solid + beverage" mean diet energy density was $1.19 \pm 0.42 \mathrm{kcal} / \mathrm{g}$, and the mean values of men were higher than women ( $p>0.05$ ). Participants' diet quality index was $47.8 \pm 9.79$ point and index scores of men were higher than women ( $p>0.05$ ). Participants with good diet quality had lower dietary energy density than those with poor diet quality ( $<0.001$ ). While a significant negative relationship was found between diet energy densities calculated by both methods and diet quality, no relationship was found between anthropometric measurements and diet quality.

Conclusion: While high dietary energy density was associated with poor diet quality, no statistically significant correlations were found with body mass index, body weight, waist/height and waist/hip ratios. Considering the studies showing the negative effects of poor diet quality and high energy density diet on health, it is important to adopt a low energy density diet that will increase diet quality. More studies are needed to reflect the relationship between dietary energy density and anthropometric measurements.

Keywords: Diet energy density, diet quality, body mass index, anthropometric measurements, nutrition

\section{GíRiş}

Dünya Sağlık Örgütü (DSÖ) sağlığı, bireylerin fiziksel, ruhsal ve sosyal olarak iyilik halinde olması şeklinde tanımlamaktadır (1). Genel sağlığı etkileyen en önemli bileşenlerden birisi yeterli ve dengeli veya diğer bir deyişle sağlıklı beslenmedir (2). Aşırı ve dengesiz beslenme ile yetersiz fiziksel aktivite, obezite ve ilişkili komorbiditelerin oluşum riskini arttırmaktadır (3). Günlük diyetle alınan enerji ve besin ögelerinin yetersiz olması durumlarında da bazı sağlık sorunları oluşmaktadır. Lüksemburg’da kardiyovasküler risk faktörlerinin ülke çapında incelendiği bir araştırmaya göre diyet kalitesinin düşük olması kronik hastalıkların görülme riskini artırırken; diyet kalitesinin yüksek olması bu riskleri azaltmaktadır (4).

Diyet kalitesi için standart bir tanımının olmamasına karşın "bir bireyin, ulusal beslenme rehberlerine uygun olarak veya bir diyet kalite skoru aracılığı ile belirlenen, genel besin alımının kalitesi” şeklinde tanımlanabilmektedir (5). Diyet kalitesinin düşük olması ve/veya diyetin enerji yoğunluğunun yüksek olması, obezite ve özellikle beslenmeye bağlı kronik hastalıkların gelişimde önemli rol oynamaktadır (6).

Besin enerji yoğunluğu bir besinin gram başına düşen enerji (kkal/g) miktarıdır. Besin enerji yoğunluğu, 0-9 kkal/g arasında değişir ve enerji yoğunluğuna en büyük katkıyı sağlayan yağlar için $9 \mathrm{kkal} / \mathrm{g}$, alkol için 7 kkal/g, karbonhidrat için $4 \mathrm{kkal} / \mathrm{g}$, protein için $4 \mathrm{kkal} /$ g’dır (7-9). Diyet enerji yoğunluğu (DEY) ise besinin içerdiği yağ ve su miktarına bağlıdır (10). Su içeriği yüksek besinlerden zengin bir diyet daha düşük enerji yoğunluğuna sahiptir. Yağların ise gramı başına sağladığı enerji miktarı diğer besin ögelerinden daha yüksektir ve dolayısıyla yağ içeriği yüksek bir diyetin enerji yoğunluğu da daha yüksektir (9).

Kesitsel tanımlayıcı tipte yapılan çoğu çalışma, yüksek enerji yoğunluklu diyetlerin enerji alımını arttırıp vücut ağırlık kazanımına ve obeziteye neden olabileceğini, düşük enerji yoğunluğunun ise daha iyi diyet kalitesiyle ilişkilendirilebileceğini göstermektedir (11-13). Yapılan bazı çalışmalara göre, 
enerji yoğunluğu (EY) yüksek besinlerin tüketimi vücut ağırlığı ve beden kütle indeksindeki (BKİ) artışla ilişkilidir (14-16). Ancak bazı çalışmalarda enerji yoğunluğu yüksek besinler ile vücut ağırlığı, vücut yağ oranı ve/veya BKİ arasında bir ilişki bulunmamıştır (17-19). İki bin on altı yılında 37 makalenin incelendiği bir sistemik derleme ve meta analiz çalışmasında ise yüksek enerji yoğunluklu bir diyetin vücut ağırlık kazanımı ve artmış adipoziteyle ilişkili olduğu; ancak BKİ ile ilişkili bulunmadığı bildirilmiştir (20).

Diyet enerji yoğunluğu yüksek bir beslenme şeklinin, kronik hastalıkların ve özellikle obezitenin gelişme riski açısından oldukça önemli olduğu bulunurken diyet enerji yoğunluğunun hesaplanmasında standart ve kabul görmüş net bir yöntem olmayışı nedeniyle literatürde diyet enerji yoğunluğu ile antropometrik ölçüm değerleri arasındaki ilişkinin incelendiği çalışmalarda farklı sonuçlar elde edildiği ve diyet kalitesi ile ilişkisinin belirlendiği yeterli çalışmanın da olmadığı görülmüştür. $\mathrm{Bu}$ amaçla bu çalışma, bireylerin DEY'nin, diyet kalitesi ve antropometrik ölçümlerle olan ilişkisini incelemek amacıyla yürütülmüştür.

\section{BIREYLER VE YÖNTEM}

Kesitsel tanımlayıcı tipte olan bu çalışmaya, gönüllü olarak katılmayı kabul eden, İstanbul'da yaşayan 1965 yaş arasındaki 271 yetişkin birey dâhil edilmiştir. Herhangi bir kronik hastalığın bulunmaması ve tıbbi tedavi alınmıyor olması, herhangi bir algılama ve iletişim sorununun olmaması araştırmaya dâhil edilme kriterleri olarak belirlenmiştir. Türkiye İstatistik Kurumu (TÜİK) verilerine göre (21) İstanbul'da yaşayan 19-65 yaş arası 5.868 .671 kişi, çalışmanın evrenini oluşturmaktadır. Araştırmanın örneklemi güç analizi yapılarak, \%94 güç, \%6 yanılma payı ile 246 kişi olarak hesaplanmıştır. Çalışmaya rastgele basit örneklem seçimine göre 271 kişi dâhil edilmiştir.

Çalışma için İstanbul Okan Üniversitesi Fen, Sosyal ve Girişimsel Olmayan Sağlık Bilimleri Araştırmaları Etik Kurulu'ndan, 11.12.2019 tarihli, 14 karar numaralı Etik Kurul Onayı alınmıştır. Veriler etik kurul onayını takip eden üç ay içinde toplanmıştır. Katılımcılara, araştırmacı diyetisyen tarafından hazırlanmış, demografik özellikler ve antropometrik ölçümlerin (boy uzunluğu, vücut ağırlığı, bel çevresi, kalça çevresi) sorgulandığı anket formu yüz yüze görüşme tekniğiyle uygulanmıştır. Bireylerden 24 saatlik geriye dönük besin tüketim kaydı alınmış, veriler Türkiye için geliştirilen "Bilgisayar Destekli Beslenme Program,, Beslenme Bilgi Sistemleri Paket Programı (BEBİS)” ile değerlendirilmiştir (22). Bireylerin diyet kaliteleri ve diyet enerji yoğunluğu besin tüketim kaydı aracılığıyla belirlenmiştir. Diyet kalitesinin belirlenmesinde "Diyet Kalite İndeksiUluslararası (Diet Quality Index-International; DKİU)" kullanılmıştır. Diyetin enerji yoğunluğu ise "sadece katı yiyecekler" ve "katı yiyecekler + içecekler" olmak üzere iki farklı hesaplama yöntemi kullanılarak hesaplanmıştır.

Bireylerin vücut ağırlığı (kg), düzenli kalibre edilen Tanita BC 601 marka taşınabilir vücut analiz cihazı, boy uzunlukları ise Seca marka boy ölçüm cihazı kullanılarak araştırmacı tarafından ölçülmüştür. Boy uzunluğu, hastanın ayaklarının yan yana ve başının Frankfurt düzleminde olmasina özen gösterilerek ölçülmüştür (23). BKİ; [vücut ağırlığı (kg)/boy uzunluğu (m)2] formülü ile hesaplanmıştır. BKİ, bel çevresi, bel/kalça ve bel/boy oranı sonuçları DSÖ’nün sınıflamasına göre yorumlanmıştır $(24,25)$.

\section{Diyet Kalite İndeksi Puanı}

"Diyet Kalite İndeksi-Uluslararası" (DKİU) diyet kalitesini değerlendiren geniş kapsamlı bir ölçek olup diyet kalitesinin uluslararası düzeyde karşılaştırılmasına olanak tanımaktadır. DKİ-U değerlendirilirken denge, yeterlilik, çeşitlilik ve genel denge olmak üzere toplamda dört ana kategori oluşturulmaktadır (26). Çeşitlilik kategorisi "besin çeşitliliğì" ve "protein grubu çeşitliliği" şeklinde iki alt kategoride değerlendirilmektedir. Besin çeşitliliğinde besin grupları beş gruba ayrılmaktadır (“sebze”, "meyve”, "et, yumurta/ tavuk, balık, kuru baklagiller”, “süt ürünleri”, “tahıl”). Protein çeşitliliği 
alt bileşeninde et/tavuk/balık/süt ürünleri/kuru baklagiller ve yumurta yer almaktadır. Yeterlilik kategorisinde, besin tüketim kaydı ile elde edilen besin ögeleri miktarları, Ulusal Bilimler Akademisi Tıp Enstitüsünün (Institute of Medicine-IOM) Önerilen Günlük Alım Miktarına (Recommended Dietary Allowances-RDA) göre karşılaştırılmaktadır. Denge kategorisinde ise besin tüketim kaydı ile elde edilen günlük diyetin "yağdan gelen enerji oranı”, “doymuş yağ asitleri”, "boş enerji kaynağı yiyecekler”, "kolesterol” ve "sodyum” (ilave sodyum dâhil) alım düzeyleri hesaplanmaktadır. Bu bölüm hesaplanırken, kategorilerin diyetle tüketilen günlük miktarları, DKİ-U ölçeğinin “denge” bölümünde yer alan ilgili alt başlıkların kesme noktalarına göre hesaplanmaktadır. Son kategori olan genel denge kategorisinde ise makro besin ögelerinin oranı ve yağ asitleri oranı incelenmektedir. Elde edilen sonuçlar; 0-20 puan çeşitlilik, 0-40 puan yeterlilik, 0-30 puan denge, 0-10 puan genel denge puanlamasına göre hesaplanmaktadır. Çalışmada diyet kaliteleri, Kim et al. (26) belirlediği toplam DKİU puan sınıflamasına göre değerlendirilmiştir. DKİ-U puanlamasından en düşük sıfır, en yüksek yüz puan alınabilmektedir. Kim et al. (26) 60 puanı mutlak kesme noktası olarak belirlemiş, 60 puanın altı “diyet kalitesi kötü”, 60 puanın üzeri "diyet kalitesi iyi” olarak sınıflandırılmıştır.

\section{Diyet Enerji Yoğunluğu}

Ledikwe et al. (27) literatürde sekiz farklı enerji yoğunluğu hesaplama yöntemi tanımlamıştır. Bunlar "sadece katı yiyecekler", "yiyecekler ve sıvı yiyecek replasmanları”, “yiyecekler ve alkol”, “yiyecekler ve meyve-sebze suları", "yiyecekler ve süt”, “yiyecekler, meyve-sebze suları ve süt”, "yiyecekler ve enerji içeren içecekler", "yiyecekler ve tüm içecekler (su hariç) (tüm besinler ve tüm enerji içeren içecekler (katı yiyecekler+içecekler)" şeklindedir. Tüm içecek kategorisinde su eklenmemektedir (27).

Diyet enerji yoğunluğu hesaplanmasında sekiz farklı hesaplama yöntemi olup kabul görmüş, standardize edilmiş net bir hesaplama yöntemi bulunmamaktadır. İçeceklerin dâhil edildiği yöntemlerin kullanılmasının genel DEY'i orantısız şekilde (yüksek enerji içeren içecekler DEY'i arttırabilir ya da kalorisiz içecekler azaltabilir) etkileyebileceğive besinler ile hastalıkların ve diğer parametrelerin ilişkisini maskeleyebileceği düşünülmektedir (28). Bu doğrultuda çalışmalarda, bu yöntemlerden en az bir tanesi uygulanacak ise "sadece katı yiyeceler"in dâhil edildiği hesaplama yönteminin kullanılması önerilmektedir (27). Öte yandan bazı yüksek enerjili içecekler de enerji yoğunluğuna katkı sağlayabilmektedir ve birden fazla yöntemin bir arada kullanılması bu yöntemler ile yapılan farklı çalışmaları karşılaştırabilmeye imkân sağlamaktadır (29,30). Bu çalışmada, DEY hesaplamada Raynor et al. (29), tarafından önerilen sınıflandırma kullanılmıştır. Bu sınıflandırmadan ilki tüm besinler ve enerji sağlayan tüm içecekleri (katı yiyecekler + içecekler) içeren, ikincisi tüm katı besinleri içeren, içecekleri içermeyen (sadece katı yiyecekler) yaklaşımdır. Meyve suları, alkollü ve alkolsüz içecekler, süt grubu içecekler vb. içecekler; çorbalar, yoğurt, dondurma ve benzeri diğer ürünler katı besinler olarak sınıflandırılmıştır $(29,31)$. Diyet enerji yoğunluğu, diyetle günlük alınan toplam enerjinin, diyetle günlük tüketilen toplam besinin gram cinsinden ağırlığına bölünmesi ile (kkal/gram) hesaplanmıştır (32).

\section{Verilerin İstatistiksel Değerlendirmesi}

Verilerin istatistik analizinde SPSS 22.0 paket programı kullanılmıştır. Nitel ve nicel değişkenlere uygun betimsel değerler tanımlanmıştır. Nitel değişkenler, sayı ve yüzde (\%) olarak, nicel değişkenler ise ortalama ve standart sapma $( \pm S S)$ şeklinde ifade edilmiştir. "Kolmogorov- Smirnov" testi ile değişkenlerin normal dağılımları değerlendirilmiştir. Normal dağılan verilerde bağımsız grupların karşılaştırılmasında independent $t$ test, normal dağılmayan verilerde ise "Mann-Whitney U testi" kullanılmıştır. Kategorik değişkenler açısından ilişki veya gruplar arası farklılıkların belirlenmesinde kikare testi uygulanmıştır. Katılımcıların diyet enerji yoğunluğunun DKİ-U puanları ve antropometrik ölçümler ile ilişkisinin belirlenmesinde Pearson 
korelasyon katsayıları hesaplanmıştır. p<0.05 önemli olarak kabul edilmiştir.

\section{BULGULAR}

$\mathrm{Bu}$ araştırma; İstanbul'da yaşayan, yaş ortalaması 27.99 \pm 10.6 yll olan 157 kadın (\%57.9), 114 erkek (\%42.1) bireyin katılımıyla gerçekleştirilmiştir. Bireyler çoğunlukla (\%72) 19-29 yaş grubundadır ve lisans (\%76) mezunudur. Bireylerin \%56.7'si öğrenci iken \%12.5’i çalışmamaktadır (Tablo 1).

Katılımcıların ortalama BKİ değerleri; kadınlarda $23.22 \pm 4.16 \mathrm{~kg} / \mathrm{m}^{2}$, erkeklerde $24.6 \pm 3.37 \mathrm{~kg} / \mathrm{m}^{2}$; ortalama bel/boy oranları kadınlarda $0.48 \pm 0.09$,erkeklerde $0.50 \pm 0.06$; bel/kalça oranları kadın ve erkekler için sirasiyla $0.80 \pm 0.08$ ve $0.90 \pm 0.08$ 'dir (Tablo 2 ).

Katılımcıların "sadece katı yiyecek" enerji yoğunluğu ortalamaları erkeklerde $(1.45 \pm 0.45 \mathrm{kkal} / \mathrm{g})$ kadınlardan $(1.41 \pm 0.51 \mathrm{kkal} / \mathrm{g})$ daha fazladır ( $\mathrm{p} 0.538)$. Aynı şekilde "katı yiyecek + içecek" enerji yoğunluğu ortalamaları da erkeklerde $(1.23 \pm 0.42 \mathrm{kkal} / \mathrm{g}) \mathrm{kad}$ nlardan $(1.16 \pm$ $0.42 \mathrm{kkal} / \mathrm{g}$ ) daha fazladır ( $\mathrm{p}=0.201$, Tablo 3 ).

Cinsiyete göre DKİ-U puan ortalamaları kadın katılımcılarda $47.3 \pm 10.01$, erkek katılımcılarda $48.49 \pm$ 9.47'dir. Erkek katılımcıların DKİU puan ortalamaları kadınlardan daha fazladır, aradaki fark ise önemli bulunmamıştır ( $p>0.05)$. Katılımcıların DKİ-U puan dağılımları incelendiğinde, kadınların \%87.3’ünün (137 kişi), erkeklerin \%87.7’sinin (100 kişi) puanlarının 60 ve altında olduğu görülmüştür ( $p>0.05$, Tablo 3).

Diyet kalite puanları 60'ın üstünde olan kadın ve erkeklerin her iki şekilde de hesaplanan diyet kalite indeksi puanları daha düşük bulunmuştur. Bu sonuç erkeklerde ve grubun genelinde istatistiksel olarak anlamlıdır ( $\mathrm{p}<0.05$, Tablo 4$)$.

Tablo 1. Katılımcıların demografik özelliklerine göre dağılımları

\begin{tabular}{llllll}
\hline & Sayı (n:271) & \% & & Sayı (n:271) & \% \\
\hline Yaş grup (yıl) & & & Ĕgitim düzeyi & & \\
$19-29$ & 195 & 72.0 & İlkokul mezunu & 12 & 4.5 \\
$30-40$ & 28 & 10.3 & Ortaokul mezunu & 9 & 3.3 \\
$41-51$ & 35 & 12.9 & Lise mezunu & 38 & 14.0 \\
$52+$ & 13 & 4.8 & Lisans mezunu & 206 & 76.0 \\
Cinsiyet & & & Lisansüstü mezunu & 6 & 2.2 \\
Kadın & 157 & 57.9 & Mesleği & & \\
Erkek & 114 & 42.1 & Öğrenci & 156 & 57.6 \\
Medeni durum & & & Çalışmıor/ev hanımı & 34 & 12.5 \\
Evli & 78 & 28.8 & İşi & 50 & 18.5 \\
Bekar & 193 & 71.2 & Memur & 31 & 11.4 \\
\hline
\end{tabular}

Tablo 2. Katılımcıların cinsiyete göre antropometrik ölçümlerinin değerlendirilmesi

\begin{tabular}{lccccc}
\hline & \multicolumn{2}{c}{ Kadın (n: 157) } & \multicolumn{2}{c}{ Erkek (n: 114) } & \multirow{2}{*}{ p } \\
\cline { 2 - 5 } & $\overline{\mathbf{X}} \pm$ SS & Alt-Üst & $\overline{\mathbf{X}} \pm$ SS & Alt-Üst & \\
\hline Boy uzunluğu (cm) & $163.91 \pm 5.49$ & $155-186$ & $178.25 \pm 6.08$ & $165-190$ & - \\
Vücut ağırlığı (kg) & $62.21 \pm 11.00$ & $40-90$ & $78.36 \pm 12.46$ & $55-130$ & - \\
Bel çevresi (cm) & $78.99 \pm 14.59$ & $58-130$ & $89.76 \pm 10.62$ & $71-125$ & - \\
Kalça çevresi (cm) & $98.41 \pm 10.76$ & $75-135$ & $100.47 \pm 7.77$ & $83-134$ & - \\
Bel/boy oranı & $0.48 \pm 0.09$ & $0.34-0.82$ & $0.50 \pm 0.06$ & $0.39-0.68$ & $0.032^{*}$ \\
Bel/kalça oranı & $0.80 \pm 0.08$ & $0.64-1.16$ & $0.90 \pm 0.08$ & $0.77-1.33$ & - \\
BKİ (kg/m $)$ & $23.22 \pm 4.16$ & $16-37.46$ & $24.6 \pm 3.37$ & $18.31-36.39$ & $0.003^{*}$ \\
\hline
\end{tabular}


Tablo 3. Katılımcıların cinsiyete göre enerji yoğunlukları ve diyet kalite indeksi puanları

\begin{tabular}{|c|c|c|c|c|c|c|c|}
\hline & \multicolumn{2}{|c|}{ Kadın (n:157) } & \multicolumn{2}{|c|}{ Erkek (n:114) } & \multicolumn{2}{|c|}{ Toplam (n:271) } & \multirow{2}{*}{$\mathbf{p}$} \\
\hline & $\overline{\mathbf{X}} \pm$ SS & Alt-Üst & $\overline{\mathbf{X}} \pm$ SS & Alt-Üst & $\overline{\mathbf{X}} \pm$ SS & Alt-Üst & \\
\hline Enerji yoğunluğu (katı) (kkal/g) & $1.41 \pm 0.51$ & $0.55-4.13$ & $1.45 \pm 0.45$ & $0.69-3.1$ & $1.43 \pm 0.49$ & $0.55-4.13$ & 0.538 \\
\hline Enerji yoğunluğu (katı+içecek) (kkal/g) & $1.16 \pm 0.42$ & $0.4-4.13$ & $1.23 \pm 0.42$ & $0.48-2.94$ & $1.19 \pm 0.42$ & $0.4-4.13$ & 0.201 \\
\hline \multirow[t]{2}{*}{ DKİ-U puan } & $47.3 \pm 10.01$ & 19-71 & $48.49 \pm 9.47$ & $27-67.5$ & $47.8 \pm 9.79$ & 19-71 & 0.325 \\
\hline & Sayı & $\%$ & Sayı & $\%$ & Sayı & $\%$ & \\
\hline DKİ-U puan $\leq 60$ & 137 & 87.3 & 100 & 87.7 & 237 & 87.5 & \multirow{2}{*}{0.911} \\
\hline DKİ-U puan $>60$ & 20 & 12.7 & 14 & 12.3 & 34 & 12.5 & \\
\hline
\end{tabular}

DKI-U: Diyet kalite indeksi uluslararası

Tablo 4. Katılımcıların cinsiyete ve diyet kalitesi puanlarına göre diyet enerji yoğunluğu ortalamaları ve standart sapmaları DKİ-U puan

\begin{tabular}{|c|c|c|c|c|c|c|c|c|c|}
\hline & \multicolumn{2}{|c|}{ Kadın (n: 157) } & \multirow{3}{*}{$\mathbf{p}$} & \multicolumn{2}{|c|}{ Erkek (n: 114) } & \multirow{3}{*}{$\mathbf{p}$} & \multicolumn{2}{|c|}{ Toplam (n: 271) } & \multirow{3}{*}{$\mathbf{p}$} \\
\hline & $\begin{array}{c}\text { DKİ-U } \\
\text { puan } \leq 60\end{array}$ & $\begin{array}{c}\text { DKİ-U } \\
\text { puan }>60\end{array}$ & & $\begin{array}{c}\text { DKİ-U } \\
\text { puan } \leq 60\end{array}$ & $\begin{array}{c}\text { DKİ-U } \\
\text { puan }>60\end{array}$ & & $\begin{array}{c}\text { DKİ-U } \\
\text { puan } \leq 60\end{array}$ & $\begin{array}{c}\text { DKİ-U } \\
\text { puan }>60\end{array}$ & \\
\hline & $\overline{\mathbf{X}} \pm \mathbf{S S}$ & $\overline{\mathbf{X}} \pm \mathbf{S S}$ & & $\overline{\mathbf{X}} \pm$ SS & $\overline{\mathbf{X}} \pm \mathbf{S S}$ & & $\overline{\mathbf{X}} \pm \mathbf{S S}$ & $\overline{\mathbf{X}} \pm$ SS & \\
\hline $\begin{array}{l}\text { Diyet enerji yoğunluğu } \\
\text { (katı) (kkal/g) }\end{array}$ & $1.44 \pm 0.52$ & $1.23 \pm 0.38$ & 0.086 & $1.49 \pm 0.45$ & $1.17 \pm 0.28$ & $0.011^{*}$ & $1.46 \pm 0.5$ & $1.2 \pm 0.34$ & $0.000^{* *}$ \\
\hline $\begin{array}{l}\text { Diyet enerji yoğunluğu } \\
\text { (katı+içecek) (kkal/g) }\end{array}$ & $1.18 \pm 0.43$ & $1.04 \pm 0.29$ & 0.142 & $1.26 \pm 0.43$ & $1.00 \pm 0.2$ & $0.000^{* *}$ & $1.22 \pm 0.43$ & $1.02 \pm 0.25$ & $0.010^{*}$ \\
\hline
\end{tabular}

DKI-U: Diyet kalite indeksi uluslararasl, ${ }^{*} p<0,05,{ }^{* *} p<0,001$

Katılımcıların genelinde her iki enerji yoğunluğu puanları ile DKİ-U puanı arasında negatif yönlü zayıf bir ilişki $\left(\mathrm{DEY}_{\text {katı }}\right.$ için $\mathrm{r}=-0.265, \mathrm{p}=0.000$; $\mathrm{DEY}_{\text {katt+içecek }}$ için $\mathrm{r}=-0.136, \mathrm{p}=0.025$ ) bulunmuştur. Kadınlarda "sadece katı yiyecek" enerji yoğunluğu puanları ile DKİ-U puanı arasında negatif yönlü zayıf bir ilişki $\left(D_{\text {katı }}\right.$ için $\left.r=-0.245, p=0.002\right)$, erkeklerde her iki enerji yoğunluğu puanları ile DKİ-U puanı arasında negatif yönlü zayıf bir ilişki $\left(\mathrm{DEY}_{\text {katı }}\right.$ için $\mathrm{r}=-0.306$, $\mathrm{p}=0.001 ; \mathrm{DEY}_{\text {katt+içecek }}$ için $\mathrm{r}=-0.204, \mathrm{p}=0.029$ ) olduğu görülmüştür ( $p<0.05$, Tablo 5).

\section{TARTIŞMA}

Düşük enerji yoğunluklu bir diyet, sağlıklı beslenmede önerilen makro besin ögeleri alım düzeyi ile uyumlu, mikro besin ögeleri açısından da oldukça zengin bir içeriğe sahiptir. Amerika'da yapılan iki büyük kohort çalışmasından 3. Ulusal Sağlık ve Beslenme Araştırması (Third National Health and Nutrition Examination Survey, NHANES-III) ve Bireylerin Besin Alımları Devam Eden Araştırması (Continuing Survey of Food Intakes by Individuals, CSFII) verilerine göre düşük enerji yoğunluklu diyetler daha yüksek diyet kalitesi ile ilişkilendirilmiştir (33,34). Bu çalışmada da diyet kalitesi kötü olan bireylerin enerji yoğunluğu, diyet kalitesi iyi olan bireylerden daha yüksek iken, diyet enerji yoğunluğu (her iki hesaplamada da) arttıkça diyet kalitesinin azaldığı tespit edilmiştir ( $p<0.05$, Tablo 4, Tablo 5).

Diyette toplam yağ tüketimi, basit şeker ve rafine karbonhidrat alımı arttıkça diyet enerji yoğunluğu artarken, posa alımı, sebze-meyve tüketimi, tam tahıllı ürünler arttıkça DEY azalmaktadır (9). Düşük posa alımı, sebze-meyve ve tam tahıl ürünlerin tüketimi ise düşük diyet kalitesi ile ilişkilidir (35). Enerji yoğunluğu düşük besinlerin tüketimi ile diyet kalitesinin artırılması önemli ve gereklidir. Aksi durumda obezite ve kronik hastalıkların gelişimi tetiklenebilmektedir (36).

Obezite sadece beslenme alışkanlıkları ile ilgili değil aynı zamanda diyet enerji yoğunluğu ile de ilgilidir (37). Yapılan çalışmalar artan enerji yoğunluğunun 
Tablo 5. Katılımcıların diyet enerji yoğunluğunun DKİ-U puan ve antropometrik ölçümler ile ilişkisi

\begin{tabular}{|c|c|c|c|c|c|c|c|c|c|c|c|c|}
\hline & \multicolumn{4}{|c|}{ Kadın (n: 157) } & \multicolumn{4}{|c|}{ Erkek (n: 114) } & \multicolumn{4}{|c|}{ Toplam (n: 271) } \\
\hline & \multicolumn{2}{|c|}{ DEY (katı) } & \multicolumn{2}{|c|}{$\begin{array}{c}\text { DEY } \\
\text { (katı+içecek) }\end{array}$} & \multicolumn{2}{|c|}{ DEY (katı) } & \multicolumn{2}{|c|}{$\begin{array}{c}\text { DEY } \\
(\text { katı+ içecek ) }\end{array}$} & \multicolumn{2}{|c|}{ DEY (katı) } & \multicolumn{2}{|c|}{$\begin{array}{c}\text { DEY } \\
\text { (katı+ içecek) }\end{array}$} \\
\hline & $\mathbf{r}$ & p & $\mathbf{r}$ & p & $\mathbf{r}$ & $\mathbf{p}$ & $\mathbf{r}$ & $\mathbf{p}$ & $\mathbf{r}$ & p & $\mathbf{r}$ & $\mathbf{p}$ \\
\hline DKİ-U puanı & -0.245 & $0.002^{*}$ & -0.098 & 0.222 & -0.306 & 0.001* & -0.204 & $0.029 *$ & -0.265 & $0.000^{* *}$ & -0.136 & $0.025^{*}$ \\
\hline Vücut ağırlığı, kg & 0.083 & 0.304 & 0.071 & 0.378 & -0.028 & 0.765 & -0.054 & 0.568 & 0.051 & 0.404 & 0.056 & 0.356 \\
\hline BKİ, kg/m² & 0.133 & 0.096 & 0.104 & 0.197 & -0.125 & 0.187 & -0.135 & 0.152 & 0.051 & 0.400 & 0.029 & 0.634 \\
\hline Bel-boy oranı & 0.095 & 0.238 & 0.091 & 0.257 & -0.112 & 0.237 & -0.116 & 0.218 & 0.040 & 0.517 & 0.035 & 0.567 \\
\hline Bel-kalça oranı & 0.075 & 0.353 & 0.116 & 0.148 & -0.133 & 0.158 & -0.143 & 0.130 & 0.015 & 0.805 & 0.048 & 0.432 \\
\hline
\end{tabular}

BKİ: Beden kütle indeksi, DKİ-U: Diyet kalite indeksi uluslararası, DEY: Diyetin enerji yoğunluğu, ${ }^{*} p<0.05,{ }^{* *} p<0.001$

bel çevresi ve artmış BKİ değerleri ile ilişkili olduğunu göstermektedir (14-16,28). ABD'de 186 kadın katılımcı ile gerçekleştirilen prospektif bir çalışmada, 6 yllda DEY yüksek olan kadınlarda (6.4 kg), düşük DEY olan kadınlara (2.5 kg) göre daha fazla vücut ağırlık kazanımı gözlenmiştir (38). Yapılan başka bir prospektif çalışmada ise DEY dörder yll ara ile üç kez hesaplanmış ve 8 yılda DEY'i yüksek olan kadınlar (6.42 kg), düşük DEY grubuna (4.57 kg) klyasla önemli derecede daha fazla vücut ağırlığı kazanmıştır (39). NHANES (2005-2008) çalışmasından elde edilen verilerin birleştirildiği, 9551 yetişkin bireyin incelendiği bir başka çalışmada ise çok düşük ve düşük enerji yoğunluğu olan besinlerin tüketiminin daha düşük BKİ ve bel çevresi ile ilişkili olduğu bulunmuştur (28). Meksika'da 2203 adölesan ile yapılan bir çalışmada ise DEY sadece katı yiyecekler ile hesaplanmış ve ortalama $1.77 \mathrm{kkal} / \mathrm{g}$ bulunmuş olup DEY ile yaşa göre BKİ Z-skoru arasında pozitif anlamlı ilişki gözlenmiştir (40). Bu çalışmada sadece katı besinlerin ortalama diyet enerji yoğunluğu $1.43 \pm$ $0.49 \mathrm{kkal} / \mathrm{g}, \mathrm{DEY}_{\text {katt+içecek }}$ ortalaması ise $1.19 \pm 0.42 \mathrm{kkal} / \mathrm{g}$ olup çalışmamızda DEY ile BKİ ve diğer antropometrik ölçümler arasında istatistiksel olarak anlamlı ilişkiler gözlenmemiştir ( $>0.05$, Tablo 3, Tablo 5). Bunun nedeni örneklem sayısının az ve yaş grubunun ise gençlerden (19-29 yaş grubu: \%72.0) oluşması olabilir.

Literatüre göre DEY, sebze ve meyve alımıyla ters orantılıyken, yağ, şekerli besin tüketimi ile pozitif ilişkilidir. Özellikle doymuş yağ tüketiminin enerji yoğunluğunun tanımlanmasında en etkili besin ögesi olduğu belirlenmiştir (35). Artmış BKİ ve bel çevresi ölçümü, düşük sebze meyve tüketimi, yüksek miktarda basit şeker, yağ ve doymuş yağ tüketimi özellikle kronik inflamatuvar hastalıklar başta olmak üzere birçok hastalıkla ilişkilidir. Bu nedenle düşük enerji yoğunluklu, posa alımının arttırıldığı, toplam yă̆ ve şeker alımının azaltıldığı Akdeniz tipi beslenme modeline benzer bir beslenmenin benimsenmesinin BKİnin ve bel çevresinin azaltılmasında ve hastalıklardan korunmada etkili olabileceği düşünülmektedir $(28,35,36)$.

Diyet enerji yoğunluğu kontrolü ile vücut ağırlığının denetimi sağlanabilmektedir. Özellikle kişilerin beslenmesi planlanırken diyetisyenler, bireylerin diyetlerini sadece enerji alım düzeyleri açısından ele almamalıdır. Enerji alım düzeyinin yanında besinlerin enerji yoğunluğu ve sıvı tüketimi de göz önünde bulundurulmalıdır. Besinlerin enerji yoğunluğu üzerine yapılan çalışmaların yetersiz olması ise bu konuda araştırma yapılması gerekliliğini ortaya koymaktadır. Enerji yoğunluğu üzerine yapılan çalışmalar ise hesaplama yöntemi göz önünde bulundurularak değerlendirilmelidir. Konunun daha net anlaşılabilmesi adına diyet enerji yoğunluğunun standart bir hesaplama yönteminin oluşturulduğu metodolojik çalışmalara, elde edilecek verilerin karşılaştırmalarının ve değerlendirmelerinin yapıldığı deneysel ve kohort çalışmalara ihtiyaç vardır.

Kesitsel tanımlayıcı tipte olan bu çalışmada diyetin enerji yoğunluğunun diyet kalitesi ile ilişkili olduğu bulunmuştur. Buna göre diyet enerji yoğunluğunun 
artışı ile diyet kalitesi azalmaktadır. Öte yandan diyet kalitesi ile antropometrik ölçüm değerleri arasında bir ilişki saptanamamıştır. Araştırmaya katılan bireylerin çoğunluğunun genç yaş grubundan ve öğrencilerden oluşması, enerji yoğunluğunu belirlemede net ve kesin bir yöntemin bulunmaması çalışmanın kısıtlılıkları arasında görülmektedir. Ayrıca çalışmanın kesitsel tanımlayıcı tipte olmasının, enerji yoğunluğunun antropometrik ölçüm değerleri ile ilişkisini belirlemede yeterli olmadığı düşünülmektedir. Öte yandan birçok çalışmada sadece katı yiyecekler ile hesaplanan DEY kullanılırken bu çalışmada iki farklı yöntemle değerlendirme yapılması çalışmanın güçlü yönlerindendir. Yapılan literatür taramasına göre bu konuda ülkemizde yapılan çalışmalar sınırlı sayıdadır. $\mathrm{Bu}$ nedenle bu çalışmanın ileride enerji yoğunluğu ile ilgili yapılacak çalışmalara örnek teşkil edecek nitelikte olduğu düşünülmektedir.

Yazarlık katkısı - Author contributions: Çalışmanın tasarımı: MPY, BAÖ; Çalışma verilerinin elde edilmesi: MPY; Verilerin analiz edilmesi: MPY, BAÖ; Makale taslağının oluşturulması: MPY, BAÖ; İ̧̧erik için eleştirel gözden geçirme: MPY, BAÖ; Yayinlanacak versiyonun son onayl: MPY, BAÖ - Study design: MPY, BAÖ; Data collection: MPY; Data analysis: $M P Y, B A O ̈$; Draft preparation: MPY, BAÖ; Critical review for content: $M P Y, B A O ̈$; Final approval of the version to be published: $M P Y, B A O ̈$.

Etik Kurul Onayı - Ethics approval: Araştırmanin yürütülebilmesi için İstanbul Okan Üniversitesi Fen, Sosyal ve Girişimsel Olmayan Sağllk Bilimleri Araştırmaları Etik Kurulu'ndan etik onay alınmıştır (Karar no:14, Karar Tarihi:11.12.2019). - Ethical approval was obtained from the Istanbul Okan University Science, Social and NonInterventional Health Sciences Research Ethics Committee to conduct the study (Decision no:14, Decision Date: 11.12.2019).

Çıkar çatışması - Conflict of interest: Yazarlar çıkar çatışması olmadığını beyan ederler. - The authors declare that they have no conflict of interest.

\section{KAYNAKLAR}

1. McCartney G, Popham F, McMaster R, Cumbers A. Defining health and health inequalities. Public Health. 2019;172:22-8.

2. Bruins MJ, Van Dael P, Eggersdorfer M. The role of nutrients in reducing the risk for noncommunicable diseases during aging. Nutrients. 2019;11(1):85.

3. Ruiz-Núñez B, Pruimboom L, Dijck-Brouwer DJ, Muskiet FA. Lifestyle and nutritional imbalances associated with Western diseases: Causes and consequences of chronic systemic low-grade inflammation in an evolutionary context. J Nutr Biochem. 2013;24(7):1183-18.

4. Alkerwi AA, Vernier C, Crichton GE, Sauvageot N, Shivappa N, Hébert JR. Cross-comparison of diet quality indices for predicting chronic disease risk: Findings from the observation of cardiovascular risk factors in Luxembourg (ORISCAV-LUX) study. Br J Nutr. 2015;113(2):259-10.

5. Leech RM, Worsley A, Timperio A, McNaughton SA. Understanding meal patterns: Definitions, methodology and impact on nutrient intake and diet quality. Nutr Res Rev. 2015;28(1):1-20.

6. Bolarić M, Šatalic Z. The relation between food price, energy density and diet quality, CJFST. 2013;5(2):39-6.

7. Bozoğlan H, Karabudak E. Yetişkin bireylerin diyet enerji yoğunluğu ile beden kütle indeksi arasındaki ilişkinin değerlendirilmesi. Bes Diy Derg. 2016; 44(3): 204-7.

8. Mendes A, Pereira JL, Fisberg RM, Marchioni DML. Dietary energy density was associated with diet quality in Brazilian adults and older adults. Appetite. 2016;97;120-6.

9. Bechthold A. Food energy density and body weight, a scientific statement from the DGE. Ernahrungs Umschau. 2014;61(1):2-10.

10. Ledikwe JH, Rolls BJ, Smiciklas-Wright H, Mitchell DC, Ard JD, Champagne C, et al. Reductions in dietary energy density are associated with weight loss in overweight and obese participants in the PREMIER trial. Am J Clin Nutr. 2007;85(5):1212-9.

11. Rolls BJ. The relationship between dietary energy density and energy intake. Physiol Behav. 2009;97(5):609-6.

12. Pérez-Escamilla R, Obbagy JE, Altman JM, Essery EV, McGrane MM, Wong YP, et al. Dietary energy density and body weight in adults and children: A systematic review. J Acad Nutr Diet. 2012;112(5):671-15.

13. O'Connor L, Walton J, Flynn A. Dietary energy density and its association with the nutritional quality of the diet of children and teenagers. J Nutr Sci. 2013;2:e10.

14. Rennie KL, Johnson L, Jebb SA. Behavioural determinants of obesity. Best Pract Res Clin Endocrinol Metab. 2005;19(3):343-15. 
15. Azadbakht L, Haghighatdoost F, Esmaillzadeh A. Dietary energy density is inversely associated with the diet quality indices among Iranian young adults. J Nutr Sci Vitaminol. 2012;58(1):29-6.

16. Boutelle KN, Fulkerson JA, Neumark-Sztainer D, Story M, French SA. Fast food for family meals: Relationships with parent and adolescent food intake, home food availability and weight status. Public Health Nutr. 2007;10(1):16-7.

17. Cuco G, Arija V, Marti-Henneberg C, Fernandez-Ballart J. Food and nutritional profile of high energy density consumers in an adult Mediterranean population. Eur J Clin Nutr. 2001;55(3):192-7.

18. Yao M, McCrory MA, Ma G, Tucker KL, Gao S, Fuss P, et al. Relative influence of diet and physical activity on body composition in urban Chinese adults. Am J Clin Nutr. 2003;77(6):1409-17.

19. Wilks DC, Mander AP, Jebb SA, Thompson SG, Sharp SJ, Turner RM, et al. Dietary energy density and adiposity: Employing bias adjustments in a meta-analysis of prospective studies. BMC Public Health. 2011;11(1):1-9.

20. Rouhani MH, Haghighatdoost F, Surkan PJ, Azadbakht L. Associations between dietary energy density and obesity: A systematic review and meta-analysis of observational studies. Nutrition. 2016;32(10):1037-10.

21. Türkiye İstatistik Kurumu (TÜİK). İllere göre nüfusun nitelikleri, 2000 genel nüfus sayımı, yaş grubu ve cinsiyete göre nüfus. Available at: https://data.tuik.gov. tr/Kategori/GetKategori?p=Nufus-ve-Demografi-109 Accessed April 10th, 2021.

22. Beslenme Bilgi Sistemleri-BEBİS. Ebispro for Windows, Stuttgart, Germany; Turkish version BEBIS; Data Bases: Bundeslebenmittelschlüssell, 11.3 And Other Sources. 2004.

23. Pekcan G. Beslenme Durumunun Saptanması. T.C. Sağlık Bakanlığı. 1. basım. Klasmat Matbaacılık, Ankara, 2008; s.3-50

24. World Health Organization (WHO). Body mass indexBMI. Available at: https://www.euro.who.int/en/healthtopics/disease-prevention/nutrition/a-healthy-lifestyle/ body-mass-index-bmi Accessed April 7th, 2021.

25. World Health Organization (WHO). Waist Circumference and Waist-Hip Ratio: Report of a WHO Expert Consultation. Geneva: World Health Organization; 2008. 39 p. Report No: VI. WHO, 2011.

26. Kim S, Haines PS, Siega-Riz AM, Popkin BM. The diet quality index international (DQI-I) provides an effective tool for crossnational comparison of diet quality as illustrated by China and the United States. J Nutr. 2003;133(11):3476-8.

27. Ledikwe JH, Blanck HM, Khan LK, Serdula MK, Seymour JD, Tohill BC, et al. Dietary energy density determined by eight calculation methods in a nationally representative United States population. J Nutr. 2005;135(2):273-5.

28. Vernarelli JA, Mitchell DC, Rolls BJ, Hartman TJ. Dietary energy density and obesity: How consumption patterns differ by body weight status. Eur J Nutr. 2018;57(1):35110.

29. Raynor HA, Van Walleghen EL, Bachman JL, Looney SM, Phelan S, Wing R. Dietary energy density and successful weight loss maintenance. Eating Behaviors. 2011;12(2):119-6.

30. Hebestreit A, Börnhorst C, Pala V, Barba G, Eiben G, Veidebaum T, et al. Dietary energy density in young children across Europe. Int J Obes. 2014;38(2):124-10.

31. Grunwald GK, Seagle HM, Peters JC, Hill JO. Quantifying and separating the effects of macronutrient composition and non-macronutrients on energy density. Br J Nutr. 2001;86(2):265-11.

32. Vernarelli JA, Mitchell DC, Rolls BJ, Hartman TJ. Methods for calculating dietary energy density in a nationally representative sample. Procedia Food Sci. 2013; 2: 68-6.

33. Kant AK, Graubard BI. Energy density of diets reported by American adults: Association with food group intake, nutrient intake, and body weight. Int J Obes. 2005;29(8):950-6.

34. Ledikwe JH, Blanck HM, Khan LK, Serdula MK, Seymour JD, Tohill BC, et al. Low-energy-density diets are associated with high diet quality in adults in the United States. J Am Diet Assoc. 2006;106(8):1172-8.

35. Hlebowicz J, Drake I, Gullberg B, Sonestedt E, Wallström $\mathrm{P}$, Persson M, et al. A high diet quality is associated with lower incidence of cardiovascular events in the Malmö diet and cancer cohort. PLoS One. 2013;8(8):e71095.

36. Du H, Ginder V, Jebb SA, Forouhi NG, Wareham NJ, Halkjaer J, et al. Dietary energy density in relation to subsequent changes of weight and waist circumference in European men and women. PLoS One. 2009;4(4):e5339.

37. Çayır A, Atak N, Köse SK. Beslenme ve Diyet Kliniğine başvuranlarda obezite durumu ve etkili faktörlerin belirlenmesi. Ankara Üniversitesi Tıp Fakültesi Mecmuası. 2011;64(1):13-7.

38. Savage JS, Marini M, Birch LL. Dietary energy density predicts women's weight change over 6 y. Am J Clin Nutr. 2008;88(3):677-7.

39. Bes-Rastrollo M, van Dam RM, Martinez-Gonzalez MA, Li TY, Sampson LL, Hu FB. Prospective study of dietary energy density and weight gain in women. Am J Clin Nutr. 2008;88(3):769-8.

40. Arango-Angarita A, Shamah-Levy T, Rodríguez-Ramírez S. Dietary energy density is associated with body mass index-for-age in Mexican adolescents. Matern Child Nutr. 2019;15(2):e12664. 